\title{
Comets and Communication: Amateur-Professional Tension in Australian Astronomy
}

\author{
Wayne Orchiston \\ Carter Observatory (The National Observatory of New Zealand), \\ PO Box 2909, Wellington, New Zealand \\ Wayne.Orchiston@vuw.ac.nz \\ Received 1998 July 13, accepted 1999 April 3
}

\begin{abstract}
Australasian amateur astronomers, Grigg and Ross, discovered four different comets between 1902 and 1907. Controversy surrounding these discoveries led to a deterioration in relations between Australia's leading amateur astronomers and Baracchi at Melbourne Observatory, and to the eventual transfer of the 'Australian Central Bureau' to Sydney Observatory.
\end{abstract}

Keywords: comets — history of astronomy

\section{Introduction}

Australian amateur astronomers have a proud history of achievement (Haynes et al. 1996), and along with their professional colleagues were the bastions of positional astronomy during the nineteenth century (see Orchiston 1989). One area in which they were particularly active was cometary astronomy, and between 1861 and 1912 all new comets discovered by Australians were detected by laymen or amateur astronomers. In addition to the comets listed in Table 1, there are some grounds for assigning the independent discovery of Comet C/1880 C1 to Dr William Bone of Castlemaine (see Orchiston 1987, 1997b).

Although staff at the Melbourne and Sydney Observatories did carry out occasional micrometric observations of known comets, most such monitoring was conducted by amateur astronomers, but particularly Abbott (Orchiston 1992), Tebbutt (Orchiston 1982), Biggs (Orchiston 1985) and Merfield. The amateurs were so enterprising that increasingly the professional observatories left cometary astronomy to their exclusive attention. When Comet 17P/Holmes appeared in southern skies in 1892, Melbourne Observatory Director, Ellery (1892), advised Tebbutt that 'The Andromeda Comet is just within our reach but we are not observing it as we know you are looking after it.' Thus, there was a healthy symbiosis, and for much of the period from 1861 to 1912 amiable amateur-professional relations prevailed in Australian astronomy (see Orchiston 1991, 1998b). The only major exception was the bitter feud which developed between Henry Russell of Sydney Observatory and John Tebbutt of Windsor (Orchiston 1988b, 1998a).

Various authors (e.g. Hetherington 1976; Lankford 1979, 1981; Rothenberg 1981) have demonstrated that the amateur-professional nexus in astronomy is a particularly fruitful area of study, addressing as it does the tensions associated with the evolution of a particular science.

This paper examines a rift that occurred between Baracchi and some of Australia's leading amateur astronomers early in the twentieth century as a result of controversy surrounding four different comets discovered by the New Zealander, John Grigg, and Melbourne's David Ross.

\section{Principal Parties in the Saga}

By the end of the nineteenth century, Melbourne and Sydney Observatories were regarded as Australia's leading professional astronomical institutions (see Haynes et al. 1996), and by international agreement Melbourne was the designated 'Australian Central Bureau'. As such, it was charged with the dissemination of topical astronomical information to leading Australian amateur astronomers and to the other Australian professional observatories. It was also responsible for advising Professor Heinrich Kreutz at the World Centre in Kiel of any comets discovered by Australian or New Zealand astronomers.

As Government Astronomer of Victoria and Director of the Melbourne Observatory, Baracchi was responsible for the successful operation of the Australian Bureau. Pietro Paolo Giovanni Earnesto Baracchi (Figure 1) was born to wealthy parents in Florence, Italy, on 1851 February 25 and studied mathematics and astronomy at school before completing a degree in Civil Engineering. He then served briefly in the Italian Army as an engineer. In 1876 Baracchi and two friends emigrated to New Zealand, but soon moved on to Melbourne. For a short time Baracchi worked at the Melbourne Observatory, but in early 1877 he 
Table 1. Australian cometary discoveries, 1861-1912

\begin{tabular}{llll}
\hline Year & \multicolumn{1}{c}{ Name } & Discoverer(s) & \multicolumn{1}{c}{ Reference } \\
\hline 1861 & $\mathrm{C} / 1861 \mathrm{~J} 1$ & Tebbutt & Orchiston (1998c) \\
1865 & $\mathrm{C} / 1865 \mathrm{~B} 1$ & Abbott & Orchiston (1997b) \\
1881 & $\mathrm{C} / 1881 \mathrm{~K} 1$ & Clevers/Thirlwall & Orchiston (1981) \\
1883 & & Ross & Orchiston (1983) \\
1884 & $\mathrm{C} / 1884 \mathrm{~A} 1$ & Davidson & Orchiston \& Brewer (1990) \\
1889 & $\mathrm{C} / 1889 \mathrm{O} 1$ & Gale & Baracchi (1914) \\
1894 & $\mathrm{C} / 1894 \mathrm{G} 1$ & Ross & Baracchi (1914) \\
1906 & $\mathrm{C} / 1906 \mathrm{~F} 1$ & Gale & Orchiston \& Brewer (1990) \\
1912 & $\mathrm{C} / 1912 \mathrm{R} 1$ & & Baracchi (1914) \\
\hline
\end{tabular}

was transferred to the Department of Lands and Survey as a draftsman and subsequently trained as a surveyor. In 1882 October, he was transferred back to the Observatory as Third Assistant. Baracchi was promoted to First Assistant in 1892, and when Ellery retired in 1895 he became Acting Director. It was only at the end of 1900 that his formal appointment as Government Astronomer of Victoria was confirmed. A leading member of the Royal Society of Victoria, he was described as a man of '... particularly likable disposition, with a genius for making friends.' (Perdrix 1979). Already of independent means, Baracchi had married the daughter of a wealthy Melbourne citizen (Merfield 1915), and after retiring in 1915 he lived in luxury until succumbing to cancer on 23 July 1926.

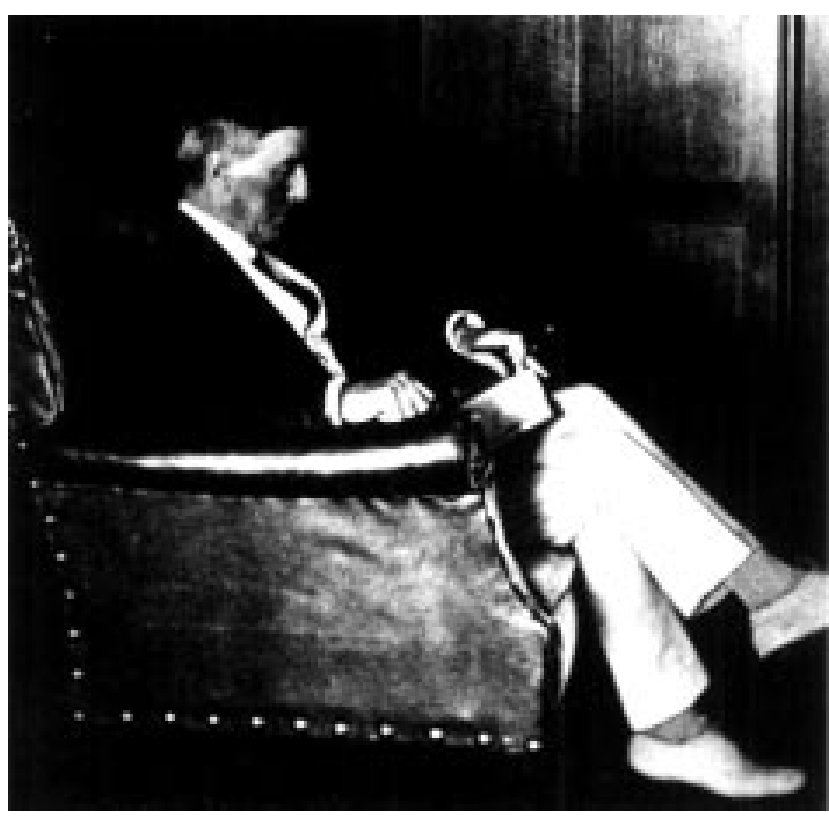

Figure 1-Pietro Baracchi (Perdrix Collection).

The issues central to this paper arose through the discoveries of four different comets between 1902 and 1907, inclusive. All four comets were independently discovered by Grigg, but Ross was able to stake a claim for the prior detection of one of these.

John Grigg (Figure 2) was born in London in 1838, and emigrated to Auckland, New Zealand, in 1863. Four years later he settled in the thriving

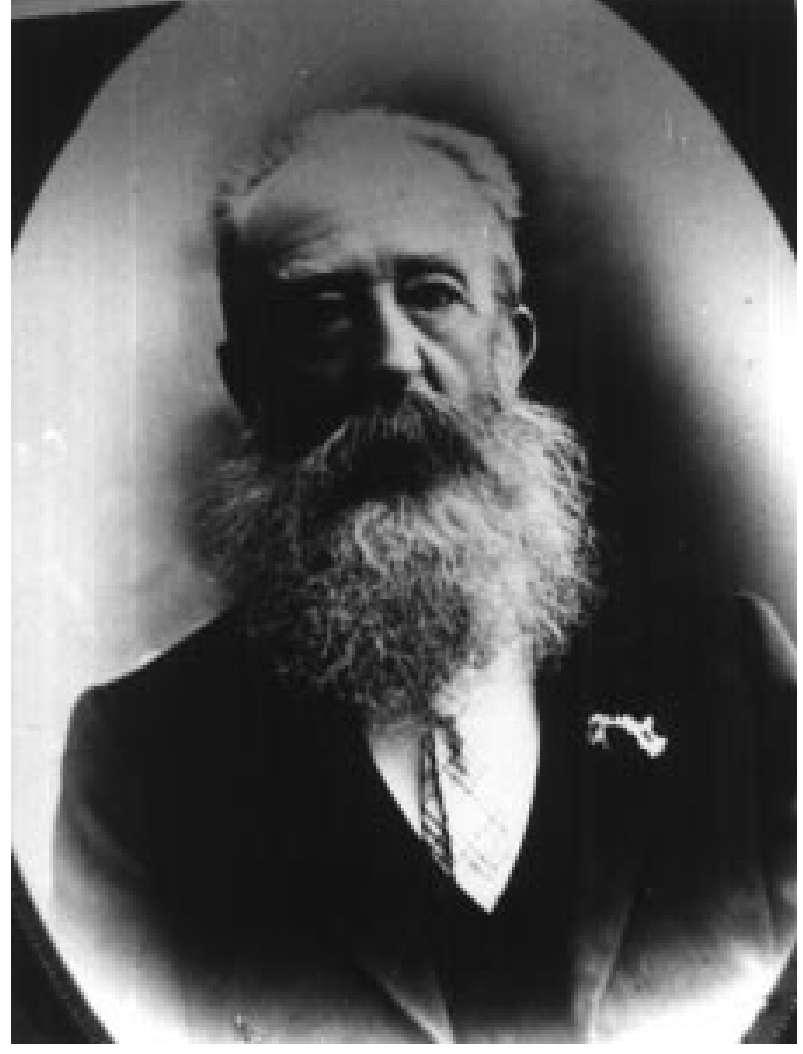

Figure 2-John Grigg (Orchiston Collection).

north island gold-mining town of Thames where he established a successful furnishing business and music store. The 1874 transit of Venus re-activated a long-standing interest in astronomy, and he went on to found an observatory which housed a $8.9 \mathrm{~cm}$ refractor and a small transit telescope. By the turn of the century he was New Zealand's leading amateur astronomer, and was an accomplished observer and populariser. He also pioneered astrophotography in New Zealand (Orchiston 1995), and acquired an international reputation for his cometary work (Orchiston 1993). In addition to independently discovering the four comets central to this paper, he was jointly responsible for the recovery of Comet 2P/Encke in 1898 (Vsekhvyatskii 1964). John Grigg died in Thames in 1920.

At about the same time that Grigg was prominent in New Zealand, David Ross (Figure 3) was Victoria's leading amateur astronomer. He was born in Ardgay, 


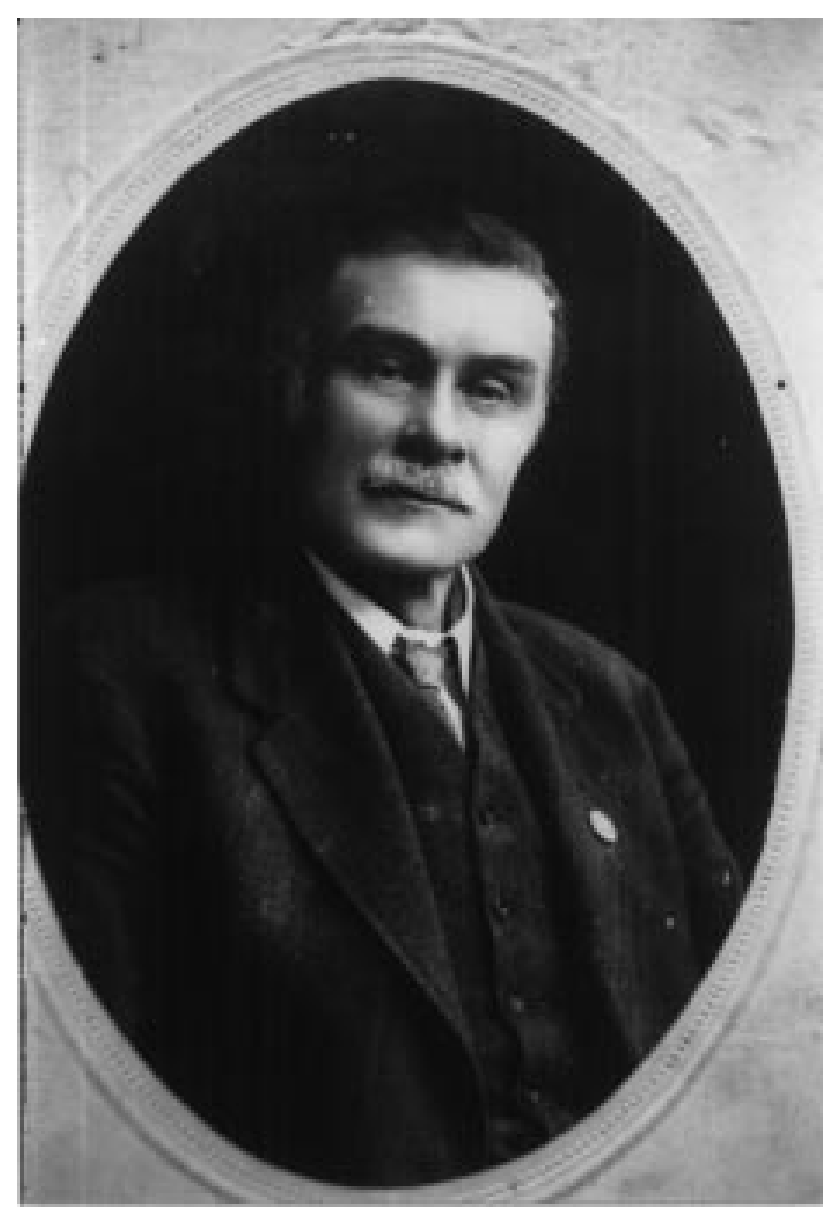

Figure 3-David Ross (Orchiston Collection).

Scotland, on 26 February 1850 and migrated to Melbourne in 1876, where he became a bank officer. During the $1870 \mathrm{~s}$ he acquired a $7 \cdot 6 \mathrm{~cm}$ refractor and from 1893 embarked on the manufacture of homemade reflectors, starting with a $22.9 \mathrm{~cm}$ instrument. By 1906 he was using an equatorially-mounted
$26 \mathrm{~cm} \mathrm{f} / 7 \cdot 8$ Newtonian reflector. Comets were Ross's primary observational interest (see Table 1 in Orchiston and Brewer 1990), and in 1884 January he discovered C/1884 A1. Occasionally he observed other solar system objects or phenomena, and he published a number of short papers in the Journal of the British Astronomical Association. During the $1890 \mathrm{~s}$, he began experimenting successfully with astronomical photography, and he was one of Australia's amateur pioneers in this field. He also played a vital role in the development of the Victoria Branch of the British Astronomical Association when this group was formed in 1897 (see Orchiston 1998b; Orchiston \& Perdrix 1990). David Ross died at Yarra Glen, near Melbourne, in 1930.

Two leading Australian astronomers who were closely involved in the controversy that surrounded the comet discoveries and played key roles in the final outcome were Tebbutt and Merfield.

By the end of the nineteenth century, John Tebbutt (Figure 4) was Australia's leading astronomer (Bhathal 1993; White 1979), despite his amateur ranking, and he had played a major role in establishing Australia's international reputation in positional astronomy. Born in Windsor, New South Wales, in 1834, at the age on nineteen he began systematic observing which led to his discovery of the C/1861 J1, the Great Comet of 1861 (Orchiston 1998c). Shortly after this, he was offered but declined the Directorship of the Sydney Observatory (Orchiston 1988b, 1998d). Determined to make his mark as an independent astronomer, he purchased a small astronomical telescope and in 1864 installed this in what was to be the first of four different Windsor Observatory buildings. Transit telescopes and two larger refractors (of $11 \cdot 4 \mathrm{~cm}$ and $20 \cdot 3 \mathrm{~cm}$ aperture) followed, and a truly staggering succession of scientific observations (mainly of comets, transits of

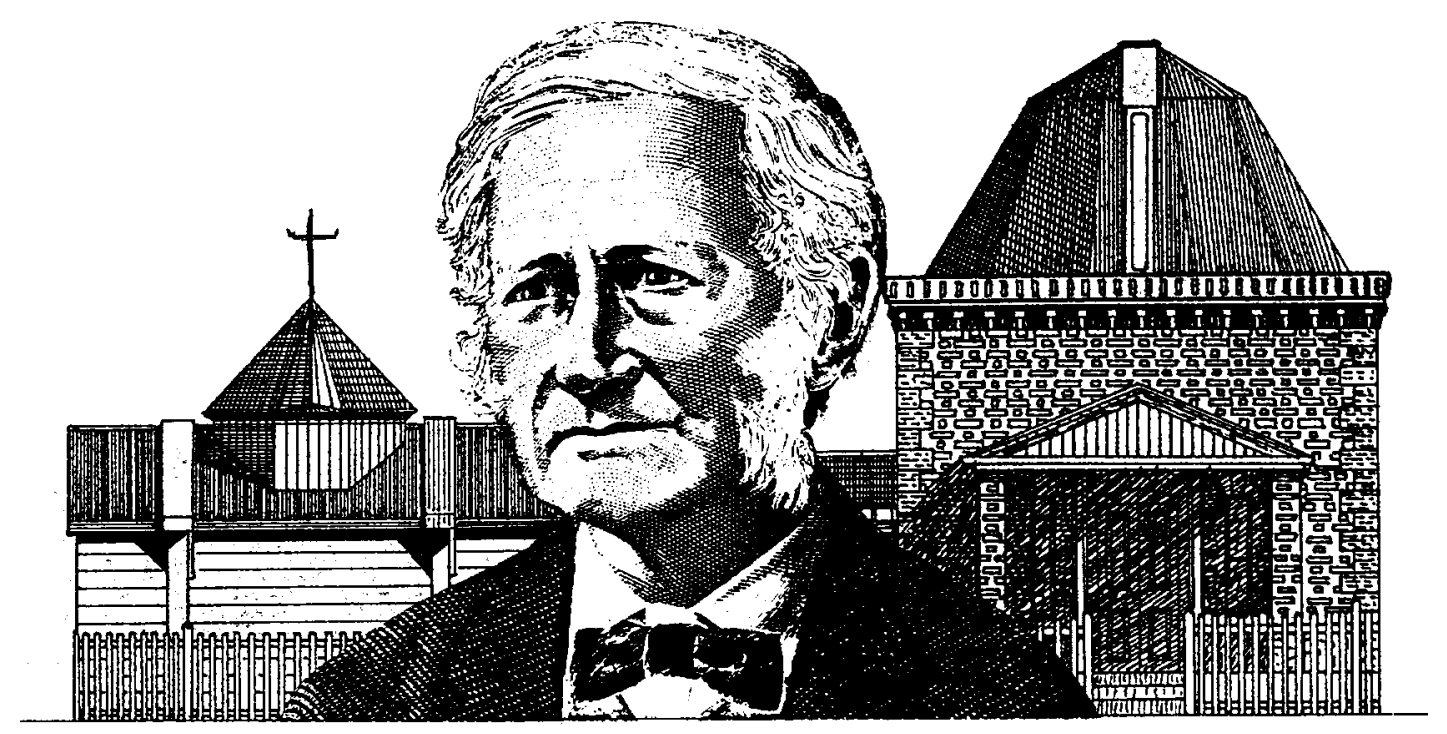

Figure 4-John Tebbutt. 
Mercury and Venus, minor planets, Jovian satellite phenomena, lunar occultations, solar and lunar eclipses, variable stars and double stars) and associated publications (e.g. see Orchiston 1982; Tebbutt 1908). In addition, in 1881 Tebbutt discovered a second Great Comet, C/1881 K1 (Orchiston 1981). He also actively popularised astronomy (Orchiston $1997 a$ ), offered a local time service, maintained a fully-equipped meteorological station, and kept records of local floods and freshes. He was the founding President of the New South Wales Branch of the British Astronomical Association (Orchiston $1988 a$ ), and was awarded the Jackson-Gwilt Medal and Gift by the Royal Astronomical Society in 1905 for his long and valuable service to astronomy. In more recent times, his face has featured on an Australian $\$ 100$ note, and a crater on the Moon has been named after him. John Tebbutt died at Windsor in 1916.

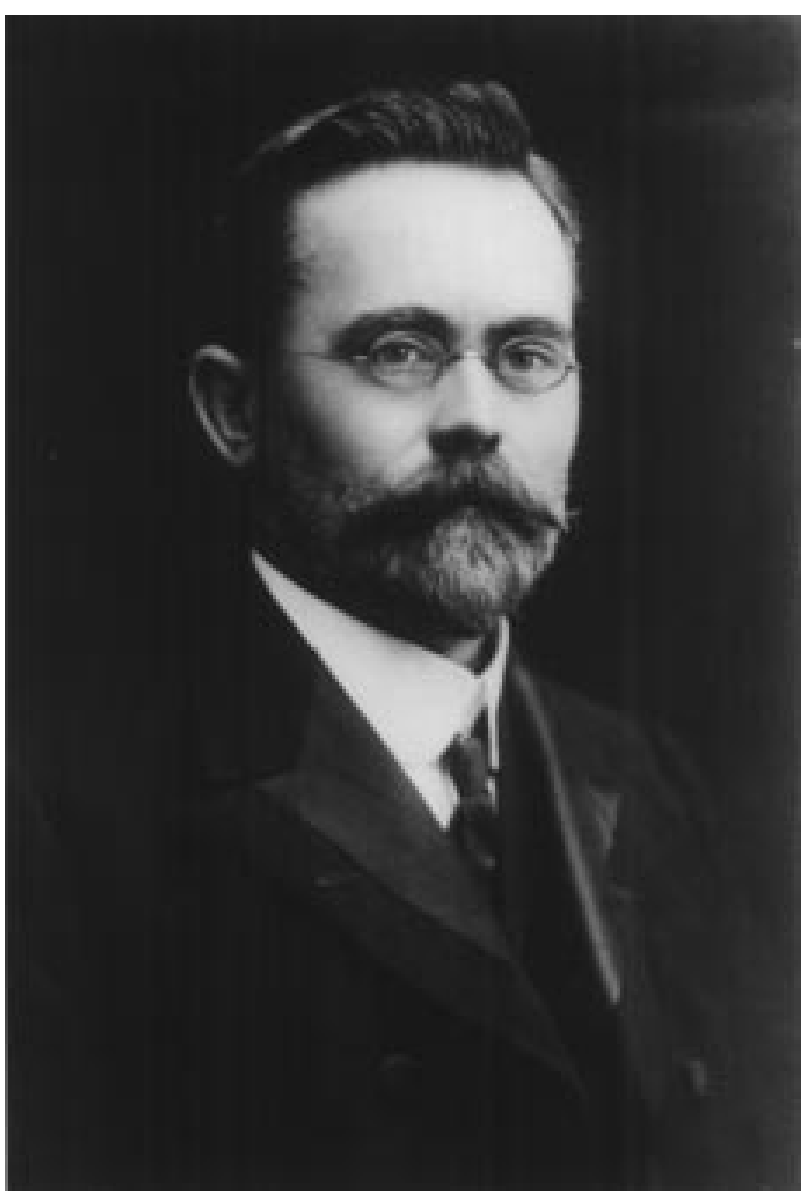

Figure 5-Charles John Merfield (Courtesy: Royal Astronomical Society Library).

Charles James Merfield (Figure 5) was one in a succession of Australian amateur astronomers to make the transition to professional ranks, and for more than thirty years was a key figure in Australian cometary astronomy, in both amateur and professional capacities. He was born in Ararat, Western Victoria on 28 April 1866, and after completing his secondary education trained in mathematics, surveying and engineering and for a number of years was employed by the Government supervising '.. the construction of new railway lines through the then virgin territory of Victoria.' (Obituaries 1932). He then moved to Sydney, and on 1890 was employed by the Public Works Department. He was assigned to the Railway Construction Department, where his mathematical prowess was particularly valued. This was to prove his entré into astronomy, in which he had a longstanding interest. His forte became the computation of definitive orbital elements of selected comets (e.g. Merfield 1901, 1902, 1903a). In 1904 he joined the staff of the Sydney Observatory, and transferred to Melbourne Observatory in 1908, eventually becoming Deputy Director. While in Sydney, Merfield was a prominent member of the New South Wales Branch of the British Astronomical Association (see Orchiston 1988a). He died tragically in a car crash in 1931.

\section{Comets and Controversy}

Details are provided below relating to the discovery, observation and documentation of the four comets that were at the centre of the controversy.

\subsection{Comet 26P/Grigg-Skjellerup}

John Grigg discovered his first comet on 1902 July 22 during monthly comet-search (Grigg 1902b) when he detected an object that looked like '... a faint nebula about twice the diameter of Jupiter.' (Grigg 1902a). Further observations were made on July 23, 26, 29 and August 1 and 2 (Grigg 1902e), and on each occasion he attempted to determine the comet's position by '.. placing the comet centrally in the field, noting the time, reading the circles of his equatorial, and then doing the same for the nearest 'Nautical Almanac' star available' (Comet Notes $1907 \mathrm{~b}$, p. 56). This crude procedure produced imprecise results, yet Grigg proceeded to use those obtained for July 23, 26 and 29 in order to calculate the comet's orbital elements, and he went on to publish these in Astronomische Nachrichten (Grigg 1902a).

Because of the suspect object's faintness in his small $8.9 \mathrm{~cm}$ refractor, and intervening bad weather, it was July 26 before Grigg was convinced that he had indeed discovered a comet and it was only then that he notified the local agent of the Press Association, and wrote to Baracchi at Melbourne Observatory and the Sydney amateur astronomer, Walter Gale. An avid telescope-maker (Orchiston \& Bembrick 1995) and populariser of astronomy (Orchiston 1997a), Gale was a committed cometary astronomer and had already discovered Comet C/1894 G1. He was also a founder of the New South Wales Branch of the British Astronomical Association (Orchiston 1988a). 
It was Baracchi's responsibility to obtain confirmation of the existence of the reported comet, assemble at least three accurate positions, cable these and other relevant discovery details to Kiel, and at the same time disseminate the assembled information to active cometary astronomers in Australia (and, in this case, in New Zealand). But when he received Grigg's letter on August 6 he wrote to John Tebbutt:

'I feel hardly justified in sending the announcement of the Discovery of this Comet to Kiel owing to the vague character of the information given by the discoverer. I wish to have your advice as to what course I should take in order to be fair to all concerned.' (Baracchi 1902a).

At the same time, despite the imprecise positions sent by Grigg, he '... made careful search over a wide area at the earliest possible opportunity...' (The comets of 1902, 1903). This proved unsuccessful, and although Tebbutt felt that Kreutz should be cabled, Baracchi hesitated. Meanwhile, Tebbutt was busy at the time with minor planet work, and '... as there were not sufficient data for finding so faint an object ...' (Tebbutt 1903) he did not search for the comet.

On 15 August 1902 Baracchi (1902b) wrote to Tebbutt that he had received a further letter from Grigg which included a position for August 3, when the comet was at the detection limit of the $8.9 \mathrm{~cm}$ refractor (see Grigg 1902b). After conducting another unsuccessful search he advised Tebbutt that he would not be cabling Kiel:

'I have not yet sent any Cable home. It seems strange to send by Cable the announcement of a discovery which occurred more than three weeks ago; and it might look foolish after so long a time, to send only an extremely rough position or positions. And moreover the Cable would probably be of little use to Astronomers at home. The only thing to consider now, is really, the justice done the discoverer; but herein, the Discoverer has himself to blame in the first instance. Under the circumstances... I shall write in full to Dr Kreutz of the Centrastelle by next mail giving all the particulars, as supplied by Mr Grigg. Please reconsider this matter in the light of what I have said above, and if you still think I should send the Cable with all the positions such as they are I promise to do so.' (ibid.)

By this time the comet was fading rapidly and it was not observed at any of the Australian amateur or professional observatories, and by the time that Baracchi's letter reached Kiel it was beyond the range of other southern hemisphere observatories.

In the end, circumstances dictated that Grigg was the sole observer of this comet, '... because he failed to communicate the discovery in time to those who were better able to make observations.' (Tebbutt 1907). Later he was to admit that he erred in not cabling Melbourne immediately he made the discovery (Grigg 1902c). Had he done so, then Barrachi could have requested confirmation of the discovery, solicited micrometric positions from Tebbutt and others, and then cabled Kiel, thus permitting other astronomers access to this comet. Even so, he should have cabled Grigg's crude particulars to Kiel in any case, instead of transmitting them by letter.

In this particular case, both Grigg and Baracchi exhibited unacceptable lapses, and as a result this comet was lost to science until its fortuitous recovery by Skjellerup on 1922 May 17 (see Orchiston 1999). Since then, Comet 26P/Grigg-Skjellerup has become one of the most researched of all the short period comets (see Hughes 1991).

Following the comet's departure in 1902, Grigg was in correspondence with Tebbutt and quickly became aware of how vital it was to supply precise positions for any newly-discovered comet. The obvious solution was to employ a micrometer, but he was quick to admit to Tebbutt that

'.. as my means were limited, I see no probability of obtaining a better outfit than I have at present so must content myself to make the best use of what I possess.' (Grigg 1902d).

What he did decide to do, in the event of finding another comet, was to make detailed drawings showing its position relative to field stars in the field, '... until I ascertain that it is under observation in a properly equipped observatory.' (ibid.).

\subsection{Comet $\mathrm{C} / 1903 \mathrm{H} 1$}

After the fiasco of his 1902 discovery Grigg appears to have learnt his lesson, and two days after he discovered his second comet, C/1903 H1 (Grigg), he cabled the following details to Baracchi: 'Comet near Zeta Eridani April seventeenth reobserved last night one and quarter degrees E.S.E.' (Baracchi 1903). This very same day, 1903 April 19, he also sent letters off to Baracchi, Tebbutt, and Gale. This time it was Baracchi who faltered, but for good reason. He found Grigg's cable

'... so mutilated and distorted when it reached me (especially the words Zeta Eridani) that it gave no clue whatever that a new comet was meant, and as a short time before I had sent the Ephemeris of Giacobini's Comet to $\mathrm{M}^{\mathrm{r}}$ Grigg, I thought that the cable probably meant an observation of Giacobini's Comet.' (Baracchi 1903).

As a result he took no action, and it was only with the arrival of Grigg's letter on April 29 that he realised his error. By this time, Gale and Tebbutt had informed colleagues and the general public of the existence of the new comet, both through private correspondence and newspaper articles. Merfield's immediately reaction was critical: 'It is a pity that $\mathrm{M}^{\mathrm{r}}$ Grigg does not give better information when he discovers a strange object, so that others may find it.' (Merfield 1903b). Yet Grigg had followed the 
correct procedure, even if '... with all my best efforts I fail to obtain close positions.' (Grigg 1903b).

With the facts before him, Baracchi (1903) was moved to action. On May 1 he received a letter from Tebbutt containing two micrometric positions, and the following day he cabled the announcement of the discovery and Tebbutt's positions to Kiel. After receiving two more positions from Tebbutt, he cabled these off on May 6. On May 9 Kiel cabled the orbital elements (based on three of Tebbutt's four positions) and Baracchi immediately passed these on Tebbutt 'and others', but it was only on May 15 that he made details of the comet widely available to Australian and New Zealand observers.

While all this was happening, Grigg was waiting to hear back from Baracchi, and in a letter to Tebbutt dated May 2 he expressed his gravest concerns:

'It is now a fortnight since I announced the discovery of an unknown Comet, and I have not yet heard of its having been observed by any other person. A cable was sent to $\mathrm{M}^{\mathrm{r}}$ Baracchi on Apl $19^{\text {th }}$ but I have not yet rec $^{\mathrm{d}}$ any acknowledgement. I hope my 'find' will not share the same fate as 1902c.' (Grigg 1903a; my italics).

Further letters in a similar vein followed on May 6, 9 and 25 (Grigg 1903b, 1903c, 1903e), and it was only on June 13 that Grigg (1903f) was able to report that about two weeks earlier he had finally heard from Baracchi! After mentioning that the telegram was mutilated Baracchi provided '... some advice as to obtaining more accurate positions and suggesting a straight bar micrometer...'. He obviously had no inkling of Grigg's financial circumstances, and seemed to have little appreciation of the stringent conditions under which the average amateur astronomer operated.

Meanwhile, Grigg was hardly impressed with Baracchi's tardiness in replying, and after reflecting on the welcome support he had already received from Tebbutt (e.g. see Grigg 1903d, 1903e), he made the following telling statement: 'It appears to me that the 'professional' does not take so much interest as the 'amateur'.' (Grigg 1903f). Shortly after this, Tebbutt learned that he was in fact the first person Grigg heard from '... in reply to his several communications to astronomers in Australia.' (Merfield 1903c).

Tebbutt continued to discuss this whole issue with Merfield, who on 26 July was moved to write:

'I cannot understand $\mathrm{M}^{\mathrm{r}}$. Baracchi, these little annoyances occur so often that one is apt to fancy that they are done for a purpose, indeed I am getting to believe that such is the case from one or two things that have taken place lately.' (Merfield 1903d).

Meanwhile, Grigg was still smarting over Baracchi's apparent indifference, and on July 22 had written:

'There is evidently a 'loose screw' in the official machinery at Melbourne. Possibly the routine work, being chiefly meteorological, is depressing and attending to the correspondence of amateur astro observers is unwelcome.... Perhaps these professional gentlemen find their time too occupied-but how different are such gentlemen as Mess ${ }^{\text {rs }}$ Crommelin, Maunder, \& others at home.' (Grigg 1903g).

Nor did the matter die there, for on October 3 Merfield (1903e) wrote yet again to Tebbutt:

'I think that the least $\mathrm{M}^{\mathrm{r}}$. Baracchi could do is to reply to your letter with regard to the bungle he made in sending cable message of certain observations comet Grigg, I must say that he makes too many of these mistakes ... his methods of procedure are peculiar and irritating to those of us who are careful and exact.'

So even though information about Comet C/1903 H1 did eventually reach Australasian astronomers, and Grigg was not the sole observer, some were disenchanted with Baracchi. At the root of the problem was his perceived unprofessional behaviour, and his attitude towards amateur astronomers.

\section{$3 \cdot 3$ Comets $C / 1905 X 1$ and $C / 1906$ F1}

Further success appeared to come Grigg's way in 1906 when he discovered a comet in Aquarius on February 10 (Grigg 1906c), and he immediately notified Baracchi as well as C. J. Merfield, who by this time was employed at the Sydney Observatory. Later he was disappointed to learn that this was in fact Comet C/1905 X1 which Giacobini had first detected on 1905 December 8 (Marsden and Williams 1996).

Less than two months later Grigg was to be disappointed yet again. On 1906 March 19 he discovered a new comet in Cetus, which '... was fairly bright in my 3-in. telescope ...' (Grigg 1906a). The following day he notified the local newspaper, and obtained a further positional observation that evening (Grigg 1906c). On March 21 he forwarded details of his discovery, and the two cometary positions to Tebbutt, noting at the time that; 'Possibly this is the comet reported from Australia as having been found in 'Sculptor' but of which no positions were given.' (Grigg 1906b). These fears proved to be correct, for David Ross (1906) of Melbourne was to stake a legitimate prior discovery claim on this comet.

Like Grigg, Ross lacked a micrometer and thus was unable to supply precise positions for Comet C/1906 F1 when he contacted the Melbourne Observatory (Merfield 1906). This exasperated Baracchi, and nearly led to Grigg being assigned the comet. The Sydney amateur astronomer, Hugh Wright, explains:

'He [Ross] said that he discovered the comet on Feb. 14, but only rough positions were obtained, \& Baracchi would not accept rough positions, nor would he search. It was only after much delay \& worrying that $\mathrm{B}$. said he would give Ross 3 minutes with the telescope to pick up the comet. He failed, the following night was cloudy, \& on the 
following night Ross showed Baracchi the object. A position was taken, \& later announced; but none too soon as Grigg of N.Z. independently detected it the following night. So officialism nearly robbed a discoverer of his credit!' (Wright 1906).

Melbourne Observatory was understaffed at the time and had a heavy observational load. Baracchi must have felt that he had better ways of spending his time than indulging David Ross, and on March 20 he wrote in uncomplimentary terms about the comet and its discoverer (see Lenehan 1906). For his part, Merfield (1906) was appalled that '... M ${ }^{\mathrm{r}}$ Ross kept his discovery so long unpublished...' and therefore inaccessible to other Australian amateur astronomers. Part of the problem was that Ross cogitated over whether he should enlist Tebbutt's support in confirming the discovery. In the end he had decided not to, on the understanding that '... you were not able for the task at your time of life, and retired from the Stage of Duty.' (Ross 1907). More than a year later he realised his error, noting in a letter to Tebbutt that 'Yet you seem to have considerable fire left in you yet.' (ibid.)!

Circumstances surrounding the discovery and publicising of this comet saw a repetition of the problems associated with Grigg's earlier comets. Ross erred greatly in delaying the announcement of his discovery, and from the start neither he nor Grigg was able to provide micrometric positions. Then, when it came time for him to carry out his assigned duties, Baracchi was reticent to do so, for once again incompetent amateur astronomers were intent on wasting his valuable time.

\section{$3 \cdot 4$ Comet C/1907 G1}

After his excellent 'communications record' in 1903 and 1906, John Grigg suffered a unexpected 'relapse' in 1907 with the arrival of C/1907 G1 (Grigg-Mellish). He discovered this comet on 1907 April 8 as a '... faint ... $15^{\prime}$ diameter ... Nebulous mass varying in distribution of brightness, but no distinct nucleus or tail.' (Kreutz 1907), and at the time noted 'It was moving with great the rapidity.' (Grigg 1907a). The American astronomer, Mellish, independently discovered this comet on April 14, and subsequently an image of it was found on a plate exposed by Professor Barnard on April 13 (see Comets of 1907, 1908).

Eager to disseminate information on the discovery, Grigg (1907b) reports that on the very evening of the discovery

'... I sent to the local newspaper office the appended report (1) which was, I believe, forwarded to the principal N.Z. papers through the Press Ass ${ }^{\mathrm{n}}$. The following evening I gave full particulars (2) which was also circulated. Next morning $10^{\text {th }} \mathrm{I}$ cabled $\mathrm{M}^{\mathrm{r}}$ Baracchi. 'Baracchi Melbourne, comet northeast alpha columbae Grigg'. This was sent as a matter of form, as I assumed my Report No 2 had been cabled across to Australia ...'
He also advised his friend J. T. Ward at the Wanganui Observatory (New Zealand), who was furnished with a $24 \cdot 1 \mathrm{~cm}$ Cooke refractor, complete with a micrometer. Ward promptly confirmed the discovery, but there is no evidence that he supplied Grigg with micrometric positions. On April 11 Grigg (ibid.) mailed details of his observations to Baracchi and Lenehan, and the following day he forwarded further information to Merfield.

John Tebbutt was the only 'obvious' Australian contact Grigg did not write to on this occasion, and he was not amused:

'... I cannot understand ... why the discoverer himself, who is a correspondent of mine and who knows that nearly all the comet observations in Australia for many years past have devolved upon me, ignores the existence of my Observatory.' (Tebbutt 1907).

When Grigg read this complaint in The Observatory he was quick to respond, explaining that he did not bother Tebbutt because he knew that the Windsor astronomer had retired from active observational astronomy but would have all relevant information anyway through reports in the Australian newspapers (Grigg 1907b). He stressed that he had directly followed the advice tendered earlier by both Barachhi and Tebbutt: that he should cable discovery details to the Melbourne Observatory. Later in the year, he took pains to point out to Tebbutt that

'... had I been a wealthy enthusiast, I might have sent full particulars by cable to several of my correspondents in the Commonwealth - andpossibly have been rewarded as I was the previous year by finding, after the lapse of six months, that the honour of the discovery had been awarded to an Australian gentleman for one days precedence, (Grigg 1907d).

Obviously the 'loss' of the 1906 comet was still a sore point, but more than this, Grigg thought it necessary to raise the financial implications of his astronomical pursuits. As a successful farmer, money was no object to Tebbutt, but Grigg's means were limited. As an outcome of their exchanges, Grigg (1907c) undertook to advise Tebbutt of any future cometary discoveries. At the time he was not to know that there would be none.

The responses by Baracchi, Lenehan and Merfield to Grigg's cable and letters were varied. There was potential danger in communicating with professional astronomers like Lenehan who possessed only rudimentary cometary knowledge, and Merfield (1907b) was astonished to discover Lenehan's response to Grigg's letter. He had written to Grigg advising that what he had observed could not have been a comet as the daily motion was too great! As Merfield (1907a) had already pointed out to Tebbutt, this was simply because 'The comet was very near to the Earth at the time of the discovery ...'.

After Tebbutt, Merfield rated at that time as Australia's leading cometary astronomer, and in 
contrast to Lenehan's inappropriate advice he acted properly. He immediately discussed the discovery with other Australian astronomers (e.g. Tebbutt 1907), some of whom had already read of it in the newspapers, and he used the crude positions supplied by Grigg to compute orbital elements and sent these to the discoverer (Merfield 1907b), to Astronomische Nachrichten (Merfield 1907e), and to the British Astronomical Association (see Comet Notes 1907a).

In contrast to Lenehan's immediate though inappropriate response and Merfield's positive and supportive attitude, Baracchi was once again weighed down by indecision. In view of the exceedingly vague position given in Grigg's cable, he decided not to cable news of the discovery to Kiel, and it was only on May 5 that he sent details off by letter (Baracchi 1907). What is more, for some reason which remained inexplicable to Merfield (1907b), Baracchi chose not to disseminate information to local astronomers when news of the discovery first reached him. Baracchi explained the circumstances in a letter to Grigg dated April 25:

'... it was cloudy the night he $\operatorname{rec}^{\mathrm{d}}$ cable \&

then he had to go up country on official business for some days. His staff were fully occupied with meridian and astrographic work \&c. He adds 'We have really no time for cometary work, and have, in fact, for years, relied on private observatories'...' (Grigg 1907b).

Grigg believed Baracchi's indecision was unacceptable: '... when he found he had to leave town, why did he not communicate with the 'private observatories' above referred to?' 'The problem was that in the past Baracchi had usually relied on Tebbutt's support, but with his retirement from systematic observational astronomy (he was 73 years of age at this time) no alternative modus operandi had been developed.

It was only when he received Merfield's orbital elements at the end of April that Baracchi was forced to act, and he promptly cabled these, and cometary positions for April 7, 11 and 15, to Kiel (Baracchi 1907). By the time he wrote to Merfield on May 6, he was having second thoughts about his actions, and regretted that he did not cable Grigg's positions when he first learned of them.

The whole unsavoury episode was unfortunate for Baracchi and for Grigg. For his part, Baracchi was exasperated by Grigg's seeming incompetence, and in a letter to Merfield dated 6 May 1907 he writes:

'Your remarks about amateurs who can't determine good positions of the objects they discover are indeed appropriate. I go much further in my appreciation of their services to astronomy. Grigg seems to be a beauty of the same type as D. Ross.' (Baracchi 1907).

Grigg, meanwhile, was very disappointed with Baracchi, and regarded his excuses for inaction as inexcusable. In a letter to Tebbutt, he pointed out that

'Some few years ago he wrote me that he was the authorised Australian representative of the Kiel centre \& requested me to cable him any future find that is the reason I entrusted the matter to him.' (Grigg 1907b; my italics).

In hindsight, it would have been safer for Grigg to have communicated initially with Merfield and/or Tebbutt, but the proper protocols had to be followed. Tebbutt (1907), who was disgusted by the whole affair, wrote: 'I cannot understand why the information was suppressed so long at the State Observatories...'. He was referring to both Melbourne and Sydney Observatories.

The overall outcome was that by the time knowledge of this comet was widespread among local astronomers it was too late, for the Moon was bright and the comet faint (Tebbutt 1907), and it had moved into northern skies, well beyond the range of southern observers (Merfield 1907b, 1907e).

\section{Discussion}

\section{1 Competence and Professionalism}

A common problem surrounding most their discoveries was that Grigg and Ross seemed incapable of quickly providing Baracchi with unambiguous reports. Nor could they supply those precise micrometric positions which were so essential for the computation of the orbital elements.

As a consequence, Baracchi was frustrated on both counts, and this led to unacceptable delays in communicating information about the Grigg and Ross comets to Kiel and in providing other Australian and New Zealand observers with requisite information. However, there was a deeper issue here, and that was the perceived research role of the amateur. With his own research commitments firmly focussed on the International Astrographic Project, these unfortunate experiences with Grigg and Ross coloured Barrachi's attitude towards amateur astronomers, and provided seeming justification for the amateur-professional dichotomy which was becoming increasingly apparent in the United States, Britain and Europe at this time.

\subsection{Consequences of the 'Shabby Treatment'}

The controversy surrounding the reporting of Comet C/1907 G1 was the last in a long series of incidents involving Baracchi, and the amateur astronomers of Sydney were particularly concerned about his recent '... shabby treatment ...' of Grigg, Ross and Tebbutt (Wright 1907b) and decided that action was necessary. While Wright (1907a) believed that Tebbutt should write to Kreutz personally and express his concerns, in the end it was group action that prevailed. The vehicle was the New South Wales Branch of the British Astronomical Association, the most dynamic of all of Australia's early astronomical 
groups and societies (see Orchiston 1988a, 1998b).

The matter came to a head at the 21 May 1907 meeting of the Branch, chaired by Merfield, and after many comments on '... $\mathrm{M}^{\mathrm{r}}$ Baracchi's remissness and want of courtesy ... during the past ten years ...' (Merfield 1907c), the following motion was passed:

'That the Committee be requested to write to Astronomical Headquarters at Kiel and suggest that Sydney be in future the Australian centre for the dissemination of information concerning comets and other astronomical news.' (Merfield 1907d).

The resulting letter to Professor Kreutz, dated May 30, read:

'... for years past there has been considerable dissatisfaction, among many people interested in astronomy in N.S.Wales and other Australian States, regarding the indifferent manner in which astronomical news has been circulated from Melbourne. [The latest Grigg incident]... is cited as one example of many that have taken place during the past ten years. This indifference on the part of the Melbourne Observatory in matters of this kind has been the means of losing many valuable observations.'

'We therefore have the honour to request, that consideration be given to the advisability of making some alteration in the location of the Australian Centre for the dissemination of astronomical news, and we further suggest that Sydney be the recognized Central Bureau.' (ibid.).

Heinrich Kreutz died on 13 July 1907, and so the letter went to his successor, Professor Kobold. He carefully considered its recommendations and acceded to these (Kobold 1907): Sydney Observatory would become the new Australian 'Central Bureau'. From Merfield's standpoint, this was a very satisfactory outcome given that he was stationed there. The irony was that the Centre would return to Victoria one year later when Merfield accepted a post at the Melbourne Observatory!

\section{Concluding Remarks}

Apart from the Russell-Tebbutt feud, amiable amateur-professional relations were a conspicuous feature of Australian astronomy during the last two decades of the nineteenth century. However, controversy surrounding four different comet discoveries early in the present century led to tension between Baracchi at Melbourne Observatory and a number of prominent Australian and New Zealand amateur astronomers. One of these was C. J. Merfield, who at the time made the transition from amateur to professional ranks, and through the New South Wales Branch of the British Astronomical Association he was able to orchestrate the transfer of the Australian 'Central Bureau' for the local dissemination of astronomical information from Melbourne Observatory to the Sydney Observatory.
This case study highlights the fragile nature of amateur-professional relations in Australian astronomy at the time; the way in which the New South Wales Branch was able to use its status as the nation' $\mathrm{s}$ foremost astronomical group to maintain a watching brief over aspects of professional astronomy and even to dictate policy; and Merfield' s emergence as an important figure in Australian astronomy.

\section{Acknowledgments}

I wish to thank the following for their assistance: Peter Hingley (Royal Astronomical Society Library), Dr Richard Dodd (Carter Observatory), John Perdrix (Perth), and staff at the Mitchell Library (Sydney). I also am grateful to the Royal Astronomical Society for permission to publish Figure 5 .

\section{References}

[The following abbreviation is used: TL $=$ Letters to John Tebbutt. Volumes of bound letters in the Mitchell Library, Sydney]

Baracchi, P. 1902a, Letter to J. Tebbutt, dated August 6, in TL

Baracchi, P. 1902b, Letter to John Tebbutt, dated August 15 , in TL

Baracchi, P. 1903, Letter to John Tebbutt, dated May 22, in TL

Baracchi, P. 1907, Letter to John Tebbutt, dated May 6, in TL

Baracchi, P. 1914, in Federal Handbook Prepared in Connection with the Eighty-Fourth Meeting of the British Association for the Advancement of Science Held in Australia, August 1914, ed. G. H. Knibbs (Melbourne: Government Printer), p. 326

Bhathal, R. 1993, Australian Astronomer John Tebbutt. The Life and Work of the Man on the $\$ 100$ Note (Sydney: Kangaroo Press)

Comet Notes 1907a, J. Brit. Astron. Assoc., 17, 368

Comet Notes 1907b, J. Brit. Astron. Assoc., 18, 55

Comets of 1902, MNRAS, 63, 241 (1903)

Comets of 1907, MNRAS, 68, 290 (1908)

Ellery, R. L. J. 1892, Letter to John Tebbutt, dated November 22 , in TL

Grigg, J. 1902a, Astronom. Nachrichten, 160, 213

Grigg, J. 1902b, Letter to John Tebbutt, dated August 12, in TL

Grigg, J. 1902c, Letter to John Tebbutt, dated September 16 , in TL

Grigg, J. 1902d, Letter to John Tebbutt, dated December 3 , in TL

Grigg, J. 1902e, Astronom. Nachrichten, 159, 389

Grigg, J. 1903a, Letter to John Tebbutt, dated May 2, in TL

Grigg, J. 1903b, Letter to John Tebbutt, dated May 6, in TL

Grigg, J. 1903c, Letter to John Tebbutt, dated May 9, in TL

Grigg, J. 1903d, Letter to John Tebbutt, dated May 23, in TL

Grigg, J. 1903e, Letter to John Tebbutt, dated May 25, in TL

Grigg, J. 1903f, Letter to John Tebbutt, dated June 13, in TL 
Grigg, J. 1903g, Letter to John Tebbutt, dated July 22, in TL

Grigg, J. 1906a, J. Brit. Astron. Assoc., 16, 319

Grigg, J. 1906b, Letter to John Tebbutt, dated March 21, in TL

Grigg, J. 1906c, J. Brit. Astron. Assoc., 16, 271

Grigg, J. 1907a, J. Brit. Astron. Assoc., 17, 364

Grigg, J. 1907b, Letter to John Tebbutt, dated May 22, in TL

Grigg, J. 1907c, Letter to John Tebbutt, dated September 19 , in TL

Grigg, J. 1907d, Letter to John Tebbutt, dated October 16, in TL

Haynes, R., Haynes, R., Malin, D., \& McGee, R. 1996, Explorers of the Southern Sky. A History of Australian Astronomy (Cambridge: Cambridge University Press)

Hetherington, N. S. 1976, J. Brit. Astron. Assoc., 86, 303

Hughes, D. W. 1991, Vistas in Astronomy, 34, 1

Kobold, H. 1907, Letter to C. J. Merfield, dated August 4, English translation in TL

Kreutz, H. 1907, Astronomische Nachrichten, 175, 175

Lankford, J. 1979, J. Brit. Astron. Assoc., 89, 574

Lankford, J. 1981, Isis, 72, 11

Lenehan, H. A. 1906, Letter to John Tebbutt, dated March 20 , in TL

Marsden, B. G., \& Williams, G. V. 1996, Catalogue of Cometary Orbits 1996 (Cambridge, Mass.: Minor Planet Center)

Merfield, C. J. 1901, Astronom. Nachrichten, 154, 229

Merfield, C. J. 1902, Astronom. Nachrichten, 157, 33

Merfield, C. J. 1903a, Astronomische Abhanlungen als Erganzungsheft zu den Astronomische Nachrichten, 4(2)

Merfield, C. J. 1903b, Letter to John Tebbutt, dated April 29 , in TL

Merfield, C. J. 1903c, Letter to John Tebbutt, dated June 8 , in TL

Merfield, C. J. 1903d, Letter to John Tebbutt, dated July 26 , in TL

Merfield, C. J. 1903e, Letter to John Tebbutt, dated October 3 , in $\mathrm{TL}$

Merfield, C. J. 1906, Letter to John Tebbutt, dated April 9 , in $\mathrm{TL}$

Merfield, C. J. 1907a, Letter to John Tebbutt, dated April 29 , in TL

Merfield, C. J. 1907b, Letter to John Tebbutt, dated May 5 , in TL

Merfield, C. J. 1907c, Letter to John Tebbutt, dated May 22 , in TL

Merfield, C. J. 1907d, Letter to John Tebbutt, dated May 30 , in TL

Merfield, C. J. 1907e, Astronom. Nachrichten, 175, 175

Merfield, C. J. 1915, Letter to John Tebbutt, dated October 8 , in TL
Obituaries 1932, MNRAS, 92, 258

Orchiston, W. 1981, J. Astron. Soc.Vic., 34, 78

Orchiston, W. 1982, Southern Stars, 29, 215

Orchiston, W. 1983, PASA, 5, 282

Orchiston, W. 1985, Records Queen Victoria Museum, 89, 1

Orchiston, W. 1987, Southern Stars, 32, 111

Orchiston, W. 1988a, J. Brit. Astron. Assoc., 98, 75

Orchiston, W. 1988b, Aust. J. Astron., 2, 149

Orchiston, W. 1989, Search, 20, 1, 16

Orchiston, W. 1991, PASA, 9, 186

Orchiston, W. 1992, Vistas Astron., 35, 315

Orchiston, W. 1993, J. Brit. Astron. Assoc., 103, 67

Orchiston, W. 1995, Aust. J. Astron., 6, 1

Orchiston, W. 1997a, Aust. J. Astron., 7, 33

Orchiston, W. 1997b, J. Brit. Astron. Assoc., 7, 115

Orchiston, W. 1998a, in Highlights of the Twenty-third General Assembly (Transactions of the International Astronomical Union), in press

Orchiston, W. 1998b, Hist. Records Aust. Sci., 25, 167

Orchiston, W. 1998c, Irish Astron. J., 1, 21

Orchiston, W. 1998d, J. Astron. History Heritage, 1, 21

Orchiston, W. 1999, J. Brit. Astron. Assoc., in press

Orchiston, W., \& Bembrick, C. 1995, J. Brit. Astron. Assoc., 6,53

Orchiston, W., \& Brewer, A. 1990, J. Brit. Astron. Assoc., 100,173

Orchiston, W., \& Perdrix, J. 1990, J. Brit. Astron. Assoc., 3,163

Perdrix, J. 1979, in Australian Dictionary of Biography. Volume 7: 1891-1939. A-Ch, ed. B. Nairn, \& G. Serle (Melbourne: Melbourne University Press), p. 166

Ross, D. 1906, J. Brit. Astron. Assoc., 16, 318

Ross, D. 1907, Letter to John Tebbutt, dated October 8, in TL

Rothenberg, M. 1981, Social Studies in Science, 11, 305

Tebbutt, J. 1903, Report of Mr Tebbutt's Observatory, The Peninsula, Windsor, New South Wales for the Year 1902 (Sydney: printed by the author)

Tebbutt, J. 1907, The Observatory, 30, 285

Tebbutt, J. 1908, Astronomical Memoirs (Sydney: printed for the author)

Vsekhvyatskii, S. K. 1964, Physical Characteristics of Comets (Jerusalem: Israel Program for Scientific Translations)

White, G. L. 1979, PASA, 3, 408

Wright, H. 1906, Letter to John Tebbutt, dated November 29 , in TL

Wright, H. 1907a, Letter to John Tebbutt, dated May 10, in $\mathrm{TL}$

Wright, H. 1907b, Letter to John Tebbutt, dated May 22, in $\mathrm{TL}$ 